\title{
Combustion of Low-heating-value Fuel in Combustor of Gas Turbine with Swirler
}

\author{
Jai-Houng Leu, ${ }^{1}$ Yan-Zuo Chang, ${ }^{2 *}$ Tian-Syung Lan, ${ }^{2}$ \\ Shi-Dong Li, ${ }^{2}$ and Ho-Sheng Chen ${ }^{2}$ \\ ${ }^{1}$ Shandong Polytechnic, No. 23000, Jin Ten East Road, Jinan City, Shandong Province 250104, China \\ ${ }^{2}$ College of Mechatronic Engineering, Guangdong University of Petrochemical Technology, \\ Maoming Guangdong 525000, China
}

(Received December 31, 2020; accepted March 19, 2021)

Keywords: combustion phenomena, low heating value, combustor design

As the concern about environmental problems and overuse of fossil fuels increases, alternative fuels with low heating values have been gaining much attention. Combusting the fuels requires modified gas turbines in terms of design and operation parameters. In this study, we aim to find appropriate parameters for designing gas turbines that combust low-heating-value fuels (LHVFs) through computer simulation. The results indicate that the jet penetration depth, inlet gas coefficient, and jet flow direction in the wall jet inlet require adjustment in the combustor design. The simulation shows that a pair of small vortices form in the front of the dome region. The length of the recirculation flow is only $0.18 D(D$ : inlet diameter of the combustor), which does not significantly affect the flame-holding ability. The results also reveal that the strength and size of the recirculation flow in the primary combustion zone must be increased as the center of the flow moves to the liner wall. The high-temperature zone must also be close to the liner, and the center of the recirculation flow must be close to the liner wall. As a result, the combustion efficiency of LHVFs in the newly designed combustor is improved by $47 \%$ from that of a conventional combustor. The results of this study are expected to lead to new innovative designs of combustors of LHVFs that save resources and reduce pollutant emission.

\section{Introduction}

Low-heating-value fuels (LHVFs) have a lower calorific value (generally less than 9000 $\mathrm{kcal} / \mathrm{m}^{3}$ ) than fossil fuels such as natural gas, coal, and petroleum. As they are chemically synthesized, LHVFs include impurities such as carbon particles and $\mathrm{H}_{2} \mathrm{~S}$. There are many kinds of LHVFs such as biomass, organic gases, and synthesized gases. ${ }^{(1)}$ As LHVFs have less effect on global warming, there have been many efforts to replace fossil fuels with LHVFs. Consonni and Larson reported that around $10 \%$ of the total electricity of the USA is provided from power generation units using LHVFs. ${ }^{(2)}$ However, using LHVFs requires modification of existing combustion systems or gas turbines to improve combustion efficiency due to their low calorific values as most LHVFs are in gaseous form.

*Corresponding author: e-mail: changyanzuo@gmail.com https://doi.org/10.18494/SAM.2021.3274 
A gas turbine with a combustion chamber is widely used to burn LHVFs as it gives better and easier control than modified combustion systems. A gas turbine is suitable for enhancing the combustion efficiency when using LHVFs as the combustion can be controlled in multiple parts of the turbine. For appropriate combustion efficiency, a swirler is needed in a gas turbine. A swirler is generally used with open flame injectors in the internal combustion engines and gas turbines of jet engines of aircraft. A swirler in a gas turbine mixes an LHVF and air and creates a flame retention effect that extends the residence time of the mixture. Thus, gas turbines with swirlers effectively regulate combustion and improve its efficiency.

Birkby et al. presented a series of computational fluid dynamics simulations of a Royce Trent industrial combustor by using the McNEWT unstructured code. ${ }^{(3)}$ The entire combustion chamber geometry including the premixing ducts, fuel injectors, and discharge nozzle was represented. Their results provided useful information on the operation of the combustor and values for combustion analysis such as the non-reacting flow field, the mixing ratio of fuel to air, and the combustion process under different operating conditions. Syred developed a gas turbine combustor with a strong precessing vortex core under an isothermal condition and suggested the equivalence premixing number. ${ }^{(4)}$ These studies and others indicated the feasibility of gas turbine swirl burners with helical coherent structures and radial axial eddies, which generate alternating rich and lean combustion to reinforce combustion under the Rayleigh criteria. However, the results were for conventional fossil fuels, not for LHVFs.

An LHVF in a gas turbine must be combusted on a large scale with precise control of the related parameters. Therefore, designing the combustion chamber (combustor) of the gas turbine requires adjustment and modification based on numerical simulations to find the design principles and parameters, along with experiments to verify the combustion efficiency and process. As a gas turbine is complicated and expensive, these simulations and experiments are critical for the practical and efficient use of LHVFs. In the experiments, state-of-the-art sensor technology is needed to accurately measure the temperature and the flow rates of air, the fuel, and the mixture. The sensor technology used in the experiments includes thermocouples for high-temperature measurement, an economizer with a micrometer for flow rate measurement, and a signal processor for calibrating the signals from the sensors. The essential information on the effects of LHVFs and air nozzles is then obtained by using the measured data for the gas turbine combustor.

Alternative fuels including LHVFs have lower calorific values than fossil fuels, so they emit less pollutants. However, existing commercial combustion systems must be modified to improve the combustion efficiency of alternative fuels. In particular, turbine combustors need modification or redesigning. The turbine combustor is an essential and expensive component of a combustion system, although it is relatively easy to modify. Sensors play an important role in the modification, as precise and accurate data are critical for designing the swirler of the gas turbine in the combustor, and a feasible design can be obtained by numerical calculation based on the data from sensors. Therefore, we investigate in this study the parameters of a gas turbine for combusting LHVFs, such as the air distribution, fuel composition, swirl number, and wallcooling flow, by using data collected from sensors to visualize the flow fields of inlet gases and simulate the combustion. The results will be helpful for future research on improving the designs 
of combustors for a variety of LHVFs, and this study provides an appropriate method for performing simulations and adjustments to enable the use of a wide range of LHVFs.

\section{Methods}

\subsection{Low-heating-value fuels}

The heating value of the gasified coal used as the LHVF (about $6300-7200 \mathrm{kcal} / \mathrm{m}^{3}$ ) in our experiments was estimated to be about $70-80 \%$ of that of coal. Methane was also tested for reference. The design parameters were adjusted according to the results of a numerical simulation of combusting the LHVF to manufacture the newly designed combustor. The combustion efficiency of the LHVF was estimated by comparing the experimental parameters obtained in the newly designed combustor and a conventional combustor.

\subsection{Combustor}

The combustor proposed by Leu ${ }^{(5)}$ was used for the experiment (Fig. 1), which is used for the non-closed reciprocating internal combustion of LHVFs. The diameter and length of the combustor are $60 \mathrm{~cm}$, and the length of the rear (secondary) combustor is $30 \mathrm{~cm}$ including the 10 $\mathrm{cm}$ rear retraction. The combustor has air and gas swirlers, a main combustion chamber (main jet), and a rear combustion chamber (secondary jet). The experiments were carried out for 24 different scenarios with heating values from $6.7 \mathrm{MJ} / \mathrm{m}^{3}\left(1600 \mathrm{kcal} / \mathrm{m}^{3}\right)$ to $25.5 \mathrm{MJ} / \mathrm{m}^{3}(6300$ $\mathrm{kcal} / \mathrm{m}^{3}$ ) and conditions from no swirling to a strong vortex (swirl number of 18.75).

\subsection{Measurement}

The influence of the air-to-fuel ratio on the adiabatic flame temperature was investigated using STANJAN software. ${ }^{(6)}$ Information on the combustion temperature in various zones of the

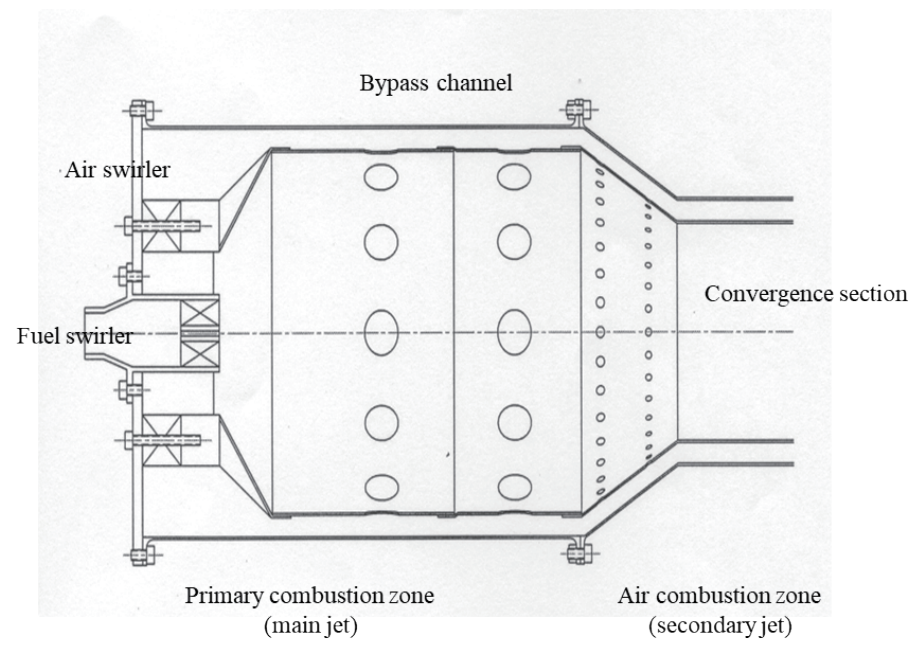

Fig. 1. Design of the combustor. 
flow field was obtained from the airflow distribution. The results provide basic information for velocity forecasting and thermal conduction analysis. Considering the overall air-to-fuel ratio of the original combustor, the average temperature in the combustor outlet was set to be lower than $427^{\circ} \mathrm{C} .{ }^{(5)}$ Table 1 illustrates the inlet conditions used in the simulation analysis of the flow field in the combustor. ${ }^{(7)}$ A K-type thermocouple (MAX6675) was used to measure the temperature in three-dimensional traversing tests. The flow rates of air and fuel were measured using a farIR economizer (CEM-06). A piezoelectric pressure sensor (SEN09376) was set up to measure the pressure. The signal from the sensors was calibrated using the Bernoulli and momentum equations, and the related parameters were estimated after detection and comparison.

For a fixed size of the combustor housing, the flame tube height is chosen after evaluating the overall combustor performance. Increasing the ratio $(K)$ of the flame tube and housing areas decreases the flow rate in the tube but increases the residence time, which improves space utilization. Reducing the pressure difference of the air through the hole is unfavorable for the mixing of air and fuel. Therefore, the optimal value of $K$ is obtained using the following equation: ${ }^{(8)}$

$$
\frac{\Delta P_{L}}{q_{P Z}}=1+\frac{T_{2} K^{2}}{T_{P Z} m_{P Z}}\left\{\frac{\Delta P_{3-4}}{q_{r e f}}-\frac{\left(1-m_{s n}\right)^{2}+\lambda\left[r^{2}(1-K)^{2}-1\right]}{(1-k)^{2}}\right\},
$$

where $T_{p z}$ is the temperature in the main combustion zone, $m_{p z}$ and $m_{s n}$ are the air ratios in the main combustion zone and vortex mixer, respectively, $r$ is the ratio of the housing area to the section area, and $\lambda$ is the coefficient of diffuser pressure loss. In our preliminary design, $m_{p z}=$ $0.227, m_{s n}=0.103, r=8.48$, and $\lambda=0.18$.

\section{Results and Discussion}

Table 2 shows the specifications for a design of the combustion system obtained using the equation proposed by Chomiak et al. ${ }^{(9)}$ Air entering the primary combustion zone is acted on by a swirler to produce a tangential velocity. To avoid energy loss caused by sudden expansion, the front-end panel angle was set at $55^{\circ}$. Using the law of momentum conservation, the swirl number

Table 1

Inlet conditions for flow-field analysis in the combustor.

\begin{tabular}{lcccccc}
\hline Inlet & Air swirler & Fuel gas & $\begin{array}{c}\text { Primary } \\
\text { cooling jet }\end{array}$ & $\begin{array}{c}\text { Penetration } \\
\text { jet }\end{array}$ & Main jet & $\begin{array}{c}\text { Secondary } \\
\text { cooling jet }\end{array}$ \\
\hline Mass $(\mathrm{kg} / \mathrm{s})$ & 0.0334 & 0.019962 & 0.0062 & 0.0921 & 0.122 & 0.0096 \\
Ratio $(\%)$ & 12.7 & 100 & 2.5 & 32.2 & 46 & 3.6 \\
Velocity & $u=7.52$ & $u=5.744$ & $v=-105.05$ & $v=-15.05$ & $v=-15.05$ & $v=-11.0$ \\
component $(\mathrm{m} / \mathrm{s})$ & $w=12.5$ & $v=4.022$ & & & \\
\hline
\end{tabular}

Penetration jet: jet flowing from the bypass into the combustion chamber

Main jet: jet penetrating into the main combustion chamber

Secondary cooling jet: jet flowing into the post-combustion chamber (mainly for cooling) 
Table 2

Design specifications of the combustion system.

\begin{tabular}{|c|c|c|c|}
\hline Item & Category & Specification & Description \\
\hline \multirow{3}{*}{ Work } & Fuel heating value & $>1500 \mathrm{kcal} / \mathrm{m}^{3}$ & Derived from tire gasification \\
\hline & System output power & $10 \mathrm{~kW}$ & Same as the original system \\
\hline & Service life & $>500 \mathrm{~h}$ & - \\
\hline \multirow{2}{*}{ Operability } & Starting & Temperature is $10-40{ }^{\circ} \mathrm{C}$ & Spark plug ignition \\
\hline & Deficient boundary & Not important & Runs at the design point \\
\hline \multirow{3}{*}{ Performance } & Efficiency of combustion & $>96 \%$ & - \\
\hline & Drop in pressure & $<9 \%$ total pressure & - \\
\hline & $\begin{array}{l}\text { Outlet temperature } \\
\text { coefficient }\end{array}$ & $<0.4$ & Can be slightly raised \\
\hline \multirow{5}{*}{ Construction } & Can shape & - & Similar to the original system \\
\hline & Size & $\begin{array}{l}\text { Outlet adapted to system } \\
\text { interface }\end{array}$ & No limit in diameter \\
\hline & Weight & No limit & Ground-mounted equipment \\
\hline & Fixing method & Similar to original system & Easy to dismantle \\
\hline & Assembly & Modular design adopted & Facilitating later adaptation \\
\hline \multirow{2}{*}{ Pollution emission } & Smoke and fog & None & - \\
\hline & NOx & Not considered & - \\
\hline
\end{tabular}

$S$ (the ratio of tangential momentum flux to axial momentum flux) of inlet air was estimated to be larger than 0.6, which would cause vortex breakdown. To avoid this, deflected gas was introduced and mixed with auxiliary gas/air to prevent damage caused by the central recirculation flow. The air jet position and distribution rate were closely related to the outlet temperature of the air. The axial distance between the main and penetration jets was $0.62 R(R$ : radius of the combustor). Table 3 illustrates the inlet conditions of the air and fuel gas at different positions under a full load.

Table 4 shows the heating values and swirl numbers for different mixtures of the LHVFs. The boundary conditions (vortex intensity) were set on the basis of numerical simulation results.

The governing equations for the airflow in the combustor were proposed by Fukue et al. ${ }^{(1)}$ The commercial software STAR-CD, a model for simulating turbulence, allows various scenarios in practical application. Although its accuracy is low due to strong numerical diffusion, it is possible to obtain a convergent solution for a combustor design. Thus, we used the STARCD SIMPLE simulation model of combustion in the solution process. ${ }^{(10)}$

The combustion system has a denser grid in the axial direction near the airflow field as air and fuel have a strong mixing shear flow. The jet flow of the inlet tends to be denser to avoid false diffusion and underestimation of the penetration depth. Also, the cooling jet that forms the airflow field structure near the outlet has a denser grid in the axial direction. In the tangential direction, the grid is divided into equal angles with three boundary conditions for the inlet, the outlet, and the cycle. Here, the average temperature, velocity, intensity, and concentration are measured, and a non-axial gradient of the combustor is assumed for the outlet condition. Finally, the conditions of the cycle at the end of the convergence section are established.

The recirculation flow moves along the centerline of the primary combustion zone. The airfuel mixture at a high temperature reversely flows to the central area of the fuel gas nozzle. The 
Table 3

Inlet conditions of air and fuel gas at different positions under full load.

\begin{tabular}{lcccccc}
\hline Inlet & Fuel gas & Air swirler & Main jet & $\begin{array}{c}\text { Penetration } \\
\text { jet }\end{array}$ & $\begin{array}{c}\text { Primary } \\
\text { cooling jet }\end{array}$ & $\begin{array}{c}\text { Secondary } \\
\text { cooling jet }\end{array}$ \\
\hline Mass $(\mathrm{kg} / \mathrm{s})$ & 0.019962 & 0.0334 & 0.122 & 0.0921 & 0.0062 & 0.0096 \\
Percent $(\%)$ & 100 & 12.7 & 46 & 32.2 & 2.5 & 3.6 \\
Velocity & $u=5.744$ & $u=7.52$ & $v=-15.05$ & $v=-15.05$ & $v=-15.05$ & $v=-11.0$ \\
component $(\mathrm{m} / \mathrm{s})$ & $v=4.022$ & $w=12.5$ & & & \\
\hline
\end{tabular}

$(u, v$, and $w$ : velocity components in $x-, y$-, and $z$-directions, respectively)

Table 4

Boundary conditions and heating values of different simulation cases.

\begin{tabular}{lccccc}
\hline Heating value & \multicolumn{5}{c}{ Swirl number } \\
\cline { 2 - 6 }$\left(\mathrm{MJ} / \mathrm{m}^{3}\right)$ & 0 & 6.25 & 9.375 & 12.5 & 18.75 \\
\hline 6.7 & LHV02 & LHV03 & LHV24 & LHV01 & LHV04 \\
11.8 & None & None & None & LHV05 & None \\
15.4 & LHV10 & LHV14 & None & LHV06 & LHV18 \\
18.9 & LHV11 & None & None & LHV07 & LHV19 \\
25.5 & LHV12 & LHV16 & None & LHV08 & LHV20 \\
\hline
\end{tabular}

main vertical jet does not appear in each tangential profile and the high-temperature mixture bypasses the main jet and the released downstream flow, as shown in Figs. 2(A)-2(D).

Owing to the staggered penetration and the main jet, a high temperature occurs on the leeward side of the main jet. A small-scale recirculation flow may cause weak flame holding. To reduce this phenomenon due to the high temperature, the combustor adopts wall jet cooling.

Figure 3 shows that the high-temperature areas are limited to the primary combustion zone and do not appear in the middle zone or near the wall of the combustor. The primary combustion zone produces two small recirculation cells with low strength. The fresh air of the main jet cannot fully return to the primary combustion zone and mixes with the fuel gas, resulting in an inadequate load in the primary combustion zone.

As shown in Figs. 2 and 3, there is a recirculation flow along the centerline of the primary combustion zone. The mixture at a high temperature reversely flows to the central area of the fuel gas nozzle, which provides an effective ignition source and causes the front wall surface of the combustor to have a high temperature. The temperature contours reveal that the highest temperature of the combustion is $1900{ }^{\circ} \mathrm{C}$. The temperature of the mixture is $100{ }^{\circ} \mathrm{C}$ higher than that of the adiabatic flame at the same inlet temperature and pressure for the conventional combustor according to the combustion simulation. The main vertical jet does not appear in each tangential profile as the high-temperature mixture bypasses the main jet and releases the flow downstream [Figs. 3(a) and 3(d)]. Thus, high-temperature areas also appear in the middle zone. Owing to the staggered jet, these high-temperature areas are separated by the penetration jet. On the leeward side of the main jet, a small-scale recirculation flow causes a weak flame. As shown in Fig. 2(B), the fluid at a high temperature is separated by the penetration jet and extends downward to the liner. This may lower the outlet temperature. 


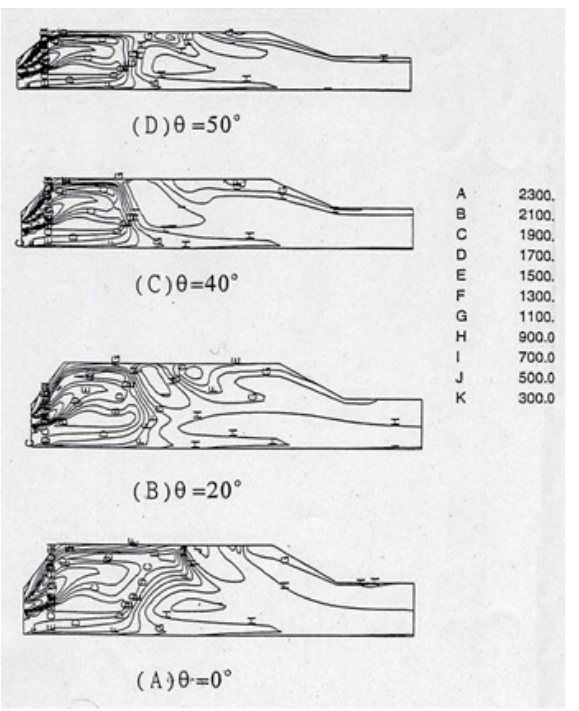

Fig. 2. Temperature contours of different tangential profiles (A to $\mathrm{K}$ represent different temperatures in Kelvin).

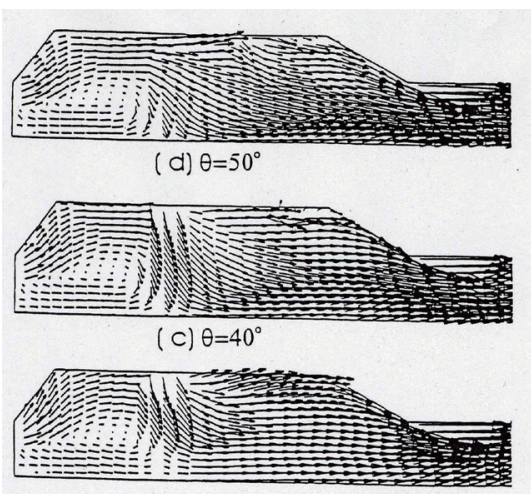

(b) $\theta=20^{\circ}$

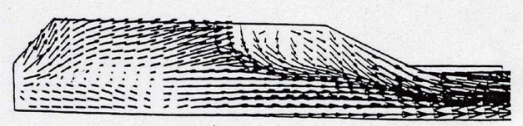

(a) $\theta=0^{\circ}$

Fig. 3. Velocity diagrams of different tangential profiles.

To solve the problem of the high temperature, the combustor adopts the method of cooling the wall with the jet as a high temperature occurs near the wall. Although the cooling jet decreases the temperature significantly, the problem may not be solved; as the highest temperature reaches $1900{ }^{\circ} \mathrm{C}$ near the front wall of the combustor, the temperature of the wall can be over $700-800$ ${ }^{\circ} \mathrm{C}$, which exceeds its temperature limit. Thus, the temperature factor is set as 0.3 to give a temperature limit of $570{ }^{\circ} \mathrm{C}\left(1900{ }^{\circ} \mathrm{C} \times 0.3=570{ }^{\circ} \mathrm{C}\right) .(5)$

The streamlines in the primary combustion zone obtained by flow visualization are shown in Fig. 4. Two groups of streamlines move around the inlet and flow back behind the rear of the inlet (Fig. 5). This is presented using the streamlines on the peripheral wall in Fig. 4.

The secondary recirculation flow moving upstream flows back and occupies most of the front dome region (Fig. 5). The recirculation structure in front of the dome region represents the main flame held in the side-inlet ramjet combustor. The flow moving into the front of the dome region coincides with the outer flow of the secondary recirculation flow from the primary recirculation flow. Owing to the high momentum of the inlet gas flow, the recirculation flows from the front of the dome region cannot disturb the inlet jet flow and cause vortex shedding. These flows are forced to flow through the passage between the two inlets. The secondary recirculation flow interferes with the primary recirculation flow. They interact with each other after temporary vibration, and then, come to balance to form a pair of vortices above and below the centerline almost symmetrically in the reverse direction (as shown in Fig. 5). These vortices are smaller than those in the front of the dome region. The length of the recirculation flow is only $0.18 D(D$ : inlet diameter of the combustor) and its structure does not affect the flameholding ability.

The characteristics of the recirculation flow in the swirler of the combustor are different from those of the shedding vortex behind the bluff bodies. The outer flow from the primary 


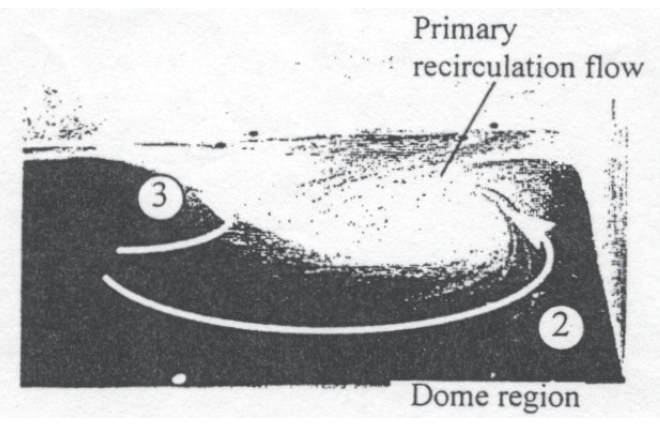

Fig. 4. Primary recirculation structures in the combustor.

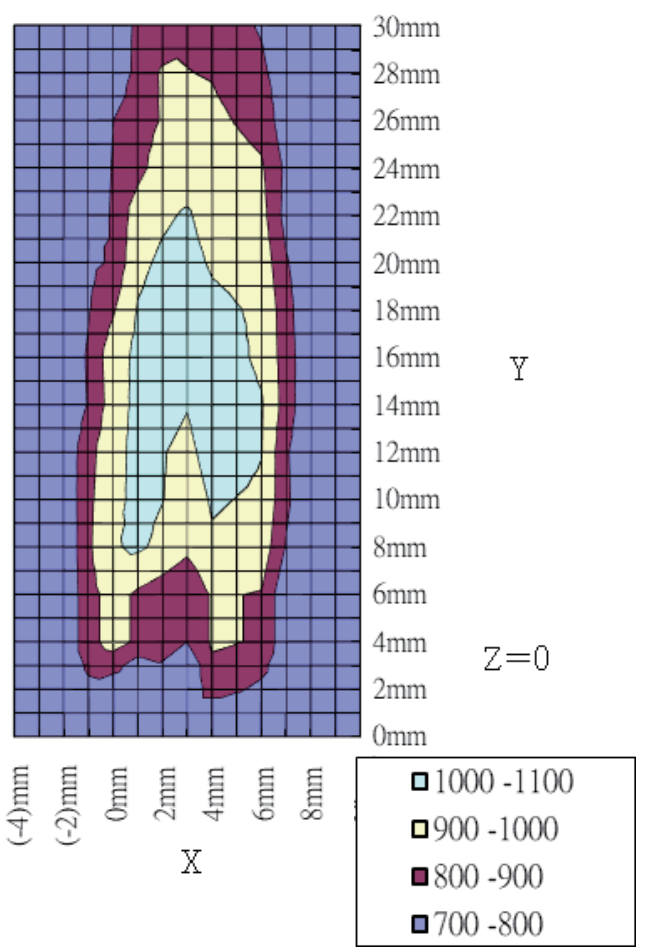

(a)
Secondary recirculation flow

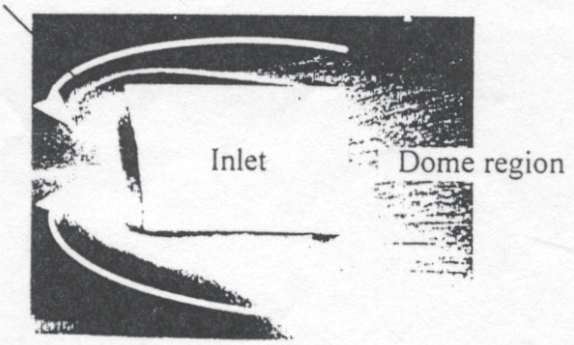

Fig. 5. Pair of recirculation flows behind the inlet.

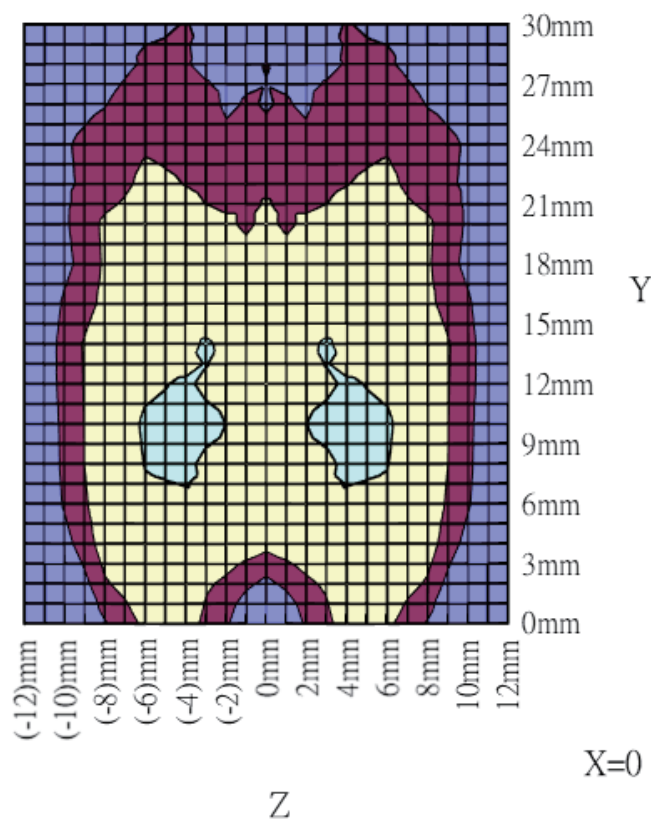

(b)

Fig. 6. (Color online) Temperature profiles (in ${ }^{\circ} \mathrm{C}$ ) at central lines for air at Reynolds number of $R e=195$ and $\mathrm{CH}_{4}$ at $R e=290$. (a) $X-Y$ plane at $Z=0$. (b) $Y-Z$ plane at $X=0$.

recirculation zone through the two jet columns is not obstructed by the inlet gas flow. Therefore, combustion instability due to the vortex-shedding process does not occur.

Figure 6 presents the temperature profiles obtained from the combustion simulation between 900 and $1100{ }^{\circ} \mathrm{C}$. They show a long and unsaturated flame with a lower combustion efficiency for the LHFVs than that of methane. The distribution of the peak temperature of the air is narrower than that of methane. This is also clearly observed under a lean combustion condition. The mass and heat transfer increase with the momentum ratio of the penetration jet to the main jet. 
The heating value of a fuel varies significantly with its biological source and manufacturing process. Many studies have focused on the integrated gasification combined cycle (IGCC) ${ }^{(11)}$ or the topping cycle. ${ }^{(12)}$ The overall combustion efficiency of the latter is higher than that of conventional coal combustion. The heating value of gasified coal is estimated to be about $70-$ $80 \%$ of that of coal. However, the results of this study showed that the combustion efficiency of LHFVs in the newly designed combustor was improved by $47 \%$ from from that of the conventional combustor.

\section{Conclusions}

A newly designed combustor for an LHVF was first optimized by numerical simulation. Then, the operation of the combustor was validated by flow visualization, combustion simulation, and experimental detection. The processes of the designed combustor were established for the LHVF of gasified coal. These processes can be applied to other LHVFs such as gasified rice husks and sawdust.

The temperature distribution of LHVFs in a combustor shows improved flame-holding ability with increasing jet penetration depth. Improving the structure of the recirculation flow in the primary combustion zone requires blocking of the effect of the wake zone as the decisive factor. The primary recirculation flow fills the front of the dome region. However, the size of the flow is much smaller than that in the front of the dome region. The vortex in the swirler of the combustor flows continuously without being processed in a shedding cycle. To validate and improve the current design concept, the optimized values for the fuel composition, swirl number, the configuration of the wall-cooling flow, and a jet flow with high penetration strength for the pre-mixing combustion must be applied to the air distribution. The results of our experiment indicate that increased penetration of the flame is disadvantagous for the mixing rate of air to fuel in the inner flame. As the fuel and air jets are located on the same side, the main reaction occurs in the fuel. Thus, the momentum ratio significantly influences the combustion efficiency. The results in this study show that the LHFVs in the newly designed combustor had higher combustion efficiency than in a commercial combustor. Even though the heating value of gasified coal is about $70-80 \%$ of that of coal, the combustion efficiency of LHVFs in the newly designed combustor was improved by $47 \%$ from that in the conventional combustor.

\section{References}

1 J. Fukue, S. Mandai, and. M. Inada: Aerothermodynamics in Combustors, Part V (Springer-Verlag, Berlin, 1991). https://doi.org/10.1007/978-3-642-84755-4

2 S. Consonni and E. D. Larson: J. Eng. Gas Turb. Power 114 (1992) 665. https://doi.org/10.1115/1.2816677

3 P. Birkby, R. S. Cant, W. N. Dawes, A. A. J. Demargne, P. C. Dhanasekaran, W. P. Kellar, N. C. Rycroft, A. M. Savill, R. L. G. M. Eggels, and I. K. Jennions: Proc. 2000 Turbo Expo (2000). https://doi.org/10.1115/2000GT-0131

4 N. Syred: Prog. Energy Combust. Sci. 32 (2006) 93. https://doi.org/10.1016/j.pecs.2005.10.002

5 J. H. Leu: J. Inf. Opt. Sci. 31 (2010) 1321. https://doi.org/10.1080/02522667.2010.10700030

6 W. C. Reynolds: Stanford University, California (1986). https://shepherd.caltech.edu/EDL/PublicResources/ sdt/refs/STANJAN_1986_Reynolds.pdf

7 X. Feng: Adv. Mat. Res. 268-270 (2011) 494. https://doi.org/10.4028/www.scientific.net/AMR.268-270.494. 
8 A. M. Starik, A. M. Savbel'ev, N. S. Titova, and U. Schumann: Aerosp. Sci. Technol. 6 (2002) 63. https://doi. org/10.1016/S1270-9638(02)01150-1

9 J. Chomiak, J. P. Longwell, and A. F. Sarofim: Prog. Energy Combust. 15 (1989) 109. https://doi. org/10.1016/0360-1285(89)90012-9

10 P. J. Jones and G. E. Whittle: Build Environ. 27 (1992) 321. https://doi.org/10.1016/0360-1323(92)90033-L

11 J. S. Kapat, A. K. Agrowal, and T. Yang: J. Eng. Gas Turb. Power 119 (1997) 20. https://doi.org/10.1115/1.2815551

12 W. F. Domeracki, T. E. Dowdy, and D. M. Bachovchin: J. Eng. Gas Turb. Power 119 (1997) 27. https://doi. org/10.1115/1.2815558 